\title{
Long-term use of multivitamins and risk of colorectal adenoma in women
}

\author{
J Massa*,1, E Cho ${ }^{2}$, E J Orav ${ }^{3,4}$, W C Willett ${ }^{1,2,5}, \mathrm{~K} \mathrm{Wu}^{1,6}$ and E L Giovannucci ${ }^{1,2,5,6}$ \\ ${ }^{1}$ Department of Nutrition, Harvard School of Public Health, 665 Huntington Ave., Boston, MA 02115, USA; ${ }^{2}$ Channing Division of \\ Network Medicine, Department of Medicine, Brigham and Women's Hospital and Harvard Medical School, 75 Francis Street, \\ Boston, MA 02115, USA; ${ }^{3}$ Department of Biostatistics, Harvard School of Public Health, 665 Huntington Ave., Boston, MA 02115, \\ USA; ${ }^{4}$ Division of General Medicine, Brigham and Women's Hospital, 75 Francis Street, Boston, MA 02115, USA and ${ }^{5}$ Department \\ of Epidemiology, Harvard School of Public Health, 665 Huntington Ave., Boston, MA 02115, USA
}

Background: Use of multivitamins may reduce the risk of colorectal adenoma, but the duration of use needed is unclear.

Methods: We prospectively examined years of multivitamin use and risk of colorectal adenoma among 43641 women who had a first endoscopy between 1991 and 2007 in the Nurses' Health Study II. Use of multivitamins was assessed through biennial questionnaires since 1989.

Results: We documented 2277 colorectal adenoma cases. Reporting multivitamin use at any time during the study period compared with never reporting its use was associated with a reduced risk of adenoma (multivariable relative risk (RR) $=0.86,95 \%$ confidence interval $(\mathrm{Cl}): 0.76-0.97)$. There was no clear trend with duration of multivitamin use: years of use compared with never use, $\leqslant 4$ years ( $R R=0.84,95 \% \mathrm{Cl}: 0.74-0.96), 5-9$ years ( $R R=0.89,95 \% \mathrm{Cl}: 0.77,1.02), 10-14$ years ( $R R=0.86,95 \% \mathrm{Cl}: 0.74,1.01)$, $15-19$ years $(R R=0.85,95 \% \mathrm{Cl}: 0.70,1.02)$, and $20-26$ years $(R R=0.80,95 \% \mathrm{Cl}: 0.64,1.01) ;(P$ trend $=0.87)$. The strongest associations (years of use vs never user) were for size of adenoma: large $(\geqslant 1 \mathrm{~cm})<4$ years $(\mathrm{RR}=0.75,95 \% \mathrm{Cl}: 0.58-0.96)$ and in alcohol users ( $\geqslant 1.4 \mathrm{~g}$ per day) $20-26$ years ( $\mathrm{RR}=0.67,95 \% \mathrm{Cl}: 0.49-0.91)$.

Conclusion: Our findings suggest that use of multivitamins is associated with lower risk of colorectal adenoma, even with relatively short duration of use.

Multivitamins contain several nutrients which are thought to affect colorectal carcinogenesis. Vitamin D may reduce the risk of colorectal cancer by increasing cell differentiation and apoptosis, decreasing cell proliferation, inhibiting angiogenesis, and through cell-cycle regulation (Holt et al, 2002; Lamprecht and Lipkin, 2003; Chlebowski et al, 2004; Grant and Garland, 2004; Giovannucci, 2006a). Folate and vitamin B6 are thought to affect colorectal carcinogenesis through the roles they have in DNA synthesis and methylation. Folate influences DNA methylation through the regeneration of methionine and functions as a coenzyme with vitamin $\mathrm{B} 6$ in the synthesis of purines, thymidylate, and DNA (Zhang et al, 2006). Deficiencies in these vitamins may result in uracil misincorporation into DNA, causing breaks in chromosomes and interference with the DNA repair process (Wickramasinghe and Fida, 1994; Blount et al, 1997; Ames, 2001). Vitamin B6 is also a cofactor for numerous physiological processes, including cell proliferation and nitric oxide synthesis, which could reduce the risk of colon cancer (Matsubara et al, 2003). It is also possible that other components of multivitamins (e.g. vitamin $\mathrm{C}$ or E) could affect colorectal carcinogenesis. This issue is of practical importance because most randomized control trials on prevention of colorectal neoplasia consider adenomas rather than cancer itself as the endpoint. Because colorectal cancer takes longer to develop than an adenoma, an effect of multivitamin use on adenomas might be seen with a shorter duration of use than one on colorectal cancer, as was seen in two older cohorts of men and women (Lee et al, 2011).

\footnotetext{
*Correspondence: Dr J Massa; E-mail: jmassa@hsph.harvard.edu

${ }^{6}$ Co-senior authors.
}

Received 1 April 2013; revised 26 September 2013; accepted 2 October 2013; published online 12 November 2013 
Many (Giovannucci et al, 1995; White et al, 1997; Giovannucci et al, 1998; Jacobs et al, 2001; Jacobs et al, 2003; Lee et al, 2011), but not all studies (Neuhouser et al, 2009), on the relationship between multivitamin use and colon cancer have found that long duration of use or long duration since first use of multivitamins was associated with lower risk of colon cancer. Results from the positive studies suggest a delayed effect of multivitamin use on the risk of colorectal cancer; however, the time relation with precursors of colorectal cancer (adenomatous polyps) is less clear (Lee et al, 2011). To our knowledge, no research has examined the duration of multivitamin use in relation to occurrences of colorectal adenoma in a young cohort. We, therefore, examined the duration of multivitamin use in relation to the occurrence of colorectal adenomas in a cohort of young women. Our primary endpoints were total adenoma and 'high-risk' adenoma (large, any mention of villous histology or high-grade dysplasia). In addition, we performed secondary analyses considering regions of the colorectum as well as types of adenoma (defined by size). In other secondary analyses, we examined whether selected characteristics (family history of colorectal cancer, physical activity, and intakes of retinol, dietary folate, and alcohol) modified the association between duration of multivitamin use and colorectal adenoma.

\section{SUBJECTS AND METHODS}

Study population. The Nurses' Health Study II (NHS II) began in 1989, when 116671 female registered nurses completed a mailed questionnaire about lifestyle factors and medical history (Colditz and Hankinson, 2005). Every 2 years participants in the NHS II were mailed follow-up questionnaires to update information on possible risk factors for disease, as well as to identify newly diagnosed illnesses. Response rates exceeded $90 \%$ for every 2 -year period. The follow up for this analysis began in 1991 when diet was first assessed through a semi-quantitative food frequency questionnaire. Participants were aged 26-46 years at the start of follow-up.

We excluded women if they did not complete a dietary questionnaire in 1991 or if they had any diagnosis of cancer (excluding nonmelanoma skin cancer), inflammatory bowel disease, familial polyposis, or colorectal polyp before 1991. We only included women who had their first lower gastrointestinal endoscopic procedure (colonoscopy or sigmoidoscopy) during the study period. After applying our exclusion criteria, 43641 women were eligible for this analysis. This study was approved by the Institutional Review Boards of the Harvard School of Public Health and the Brigham and Women's Hospital.

Ascertainment of colorectal adenoma cases and controls. The ascertainment of adenoma cases and controls has been previously described (Giovannucci et al, 1993). Briefly, on each biennial questionnaire, we inquired about the indications for the procedure; whether colon or rectal polyps had been diagnosed; and, if so, the date of diagnosis. Women who indicated a new diagnosis of colorectal polyp on a follow-up questionnaire were mailed a consent form to ask for medical records. Study investigators, who were blinded to the exposure status of the women, reviewed the records and collected information on the anatomic location, histological type, and size of the reported polyps. Only those adenoma cases that were confirmed by pathology report were considered in this analysis. Only those women in the NHS II who had their first endoscopy procedure during the study period are included in this investigation; repeat endoscopies are not considered. Between 1991 and 2007, we documented 2277 women with adenomas in the proximal or distal colon or rectum, or any combination of the three locations diagnosed during their first endoscopy. We documented 1011 proximal colon, 1107 distal colon, and 398 rectal adenomas; cases can have adenomas counted in multiple locations. In total, 1599 women were classified as having all small $(<1 \mathrm{~cm})$ adenomas, 556 women had one or more large $(\geqslant 1 \mathrm{~cm})$ adenoma, and 122 women had missing information on adenoma size, mainly as a result of biopsy procedures which left the size inestimable. In total, 1090 were classified as having low risk (small and tubular), 696 had high risk (large, any mention of villous histology or highgrade dysplasia), and 491 women had missing information on adenoma stage because of similar issues with biopsy procedures. Non-cases consisted of women who did not have adenoma detected during their first endoscopy, although they may have had adenoma diagnosed at a later endoscopy or had hyperplastic polyps. Two thousand one hundred and fifty-four women had missing information on years of multivitamin use and were excluded from analyses.

Assessment of multivitamin use and duration. At the beginning of the NHS II study in 1989, a questionnaire was mailed to participants to collect information on lifestyle factors, disease status, and current use of vitamin supplement use, including the duration of use. Current multivitamin use was additionally assessed in the biennial questionnaires, which were administered between 1991 and 2005. We also collected data on specific brands and types of multivitamin supplements (Willett et al, 1985; Salvini et al, 1989).

Total duration of multivitamin use was calculated by adding the 'past' years of use with 'current' years of use. The number of 'past' years was first obtained from the 1989 questionnaire, on which participants were asked if they currently take a multivitamin and for the duration of time they had been taking it $(0-1,2-4,5-9$, or $10+$ years). If a participant answered 'yes' to being a current user, but did not provide the duration of years use, she was assigned to be missing for duration. The $10+$ years' time interval was considered as 10 years; however, the remaining 'past' use time intervals were calculated for all participants by using the midpoint number of years for each of these intervals $(0-1$ was considered as 0.5 years, $2-4$ was considered as 3 years, 5-9 was considered as 7 years). The 'current' usage years were updated from information obtained from the current user (yes/no) question from each biennial follow up questionnaire starting in 1991 through 2005; for each questionnaire cycle that the participant responded 'yes' to current user, we added 2 additional years onto her years of total multivitamin use. For example, if a participant reported having been a multivitamin user for the previous 2-4 years in 1989, we would take the median value of this range, 3 years, for her 'past' usage component. If this same respondent reported being a nonuser in 1991, 1993, and 1995 but reported being a user in 1997 and 1999, her total years of 'current' multivitamin use from these questionnaires would be $0+0+0+2+2$ to total 4 years. Then we would add her 3 years of reported use from 1989 and combine them with her 4 years from 1997 and 1999 for a final estimate of duration of multivitamin use of 7 years as of 1999 .

Assessment of other covariates. Information on height, body weight, recreational physical activity, smoking (including number of packs of cigarettes and years smoked), aspirin use, and region of residence to estimate solar ultraviolet radiation were collected on biannual questionnaires. Body mass index (BMI; $\mathrm{kg} \mathrm{m}^{-2}$ ) was calculated using height and weight. Solar ultraviolet radiation (UV-B in Robertson-Berger meter units) was collected from 30 photosensitive meters across the UnitedStates and was matched to the place of residence (Scotto et al, 1988). Dietary information was collected from the participants using validated semi-quantitative food which were administered during 1991, 1995, 1999, and 2003. These questionnaires listed about 130 foods and beverages. 
Women were asked, on average, how often over the past year they consumed a commonly used unit or portion size of each item. Nutrient intakes were then computed by multiplying the consumption frequency of each unit of every food by the nutrient content of the specified portions using composition values from the U.S. Department of Agriculture and additional sources (Willett et al, 1985; Agriculture, 1989). Cumulative averaging of all available dietary measures up to the start of each 2 -year interval was used to obtain the most accurate representation of the women's long-term dietary pattern.

Statistical analysis. We analysed total years of multivitamin use in relation to the risk of colorectal adenoma for the main analysis, and then performed separate analyses of adenomas in the proximal colon, distal colon, and rectum. In addition, we stratified by size and high-/low-risk pathologic features of adenomas. Large adenomas were defined as $\geqslant 1 \mathrm{~cm}$, small as $<1 \mathrm{~cm}$, high risk were defined as large or any mention of villous histology or highgrade dysplasia, and finally low risk as small and tubular. Multivariable logistic regression models were used to calculate odds ratios to approximate relative risks (RRs) of diagnosed adenoma in the large bowel. To control for potential confounders, we created one model with known non-dietary risk factors for adenoma: age in 5-year intervals, time period of endoscopy (2-year study period interval), reason for first endoscopy (screening vs symptoms), family history of colorectal cancer (first-degree relative), height (categories in inches: 39-62, 63-64, 65-66, and 67-81), BMI (quintiles), physical activity (MET- $\mathrm{h}$ per week in quintiles), pack-years of smoking (quintiles of packs of cigarettes smoked per year), aspirin use (never, past only, current use 1 day per week, current use 2-3 days per week, current use 4-5 days per week, and current use $\geqslant 6$ days per week), and UV-B (RobertsonBerger meter units in quintiles). A second model was developed which included all of the previously mentioned non-dietary factors as well as dietary variables that could be confounders; these included: intake of energy-adjusted calcium (milligrams (mg) per day in quintiles), dietary folate (from food not supplements) (micrograms (mcg) per day in quintiles), alcohol (grams (g) per day in categories: $0,>0$ to $<5,5$ to $<15$, and $\geqslant 15$ ), unprocessed red meat and processed meats (servings per day in quintiles). We also performed restricted cubic spline analyses to investigate a nonlinear relationship between years of multivitamin use and risk of colorectal adenoma.

In addition, in subgroup analyses we examined whether selected cumulative updated characteristics (family history of colorectal cancer, physical activity, and intakes of retinol, dietary folate, and alcohol) modified the association between duration of multivitamin use and colorectal adenoma. We used medians of selected characteristics to create each subgroup. We tested if the association between multivitamin use and colorectal adenoma differed by family history by using this variable to stratify the fully adjusted multivariable model, using years of multivitamin use as a continuous variable, and performing a Wald test to compare the years of multivitamin use estimates. We tested whether the association between multivitamin use and colorectal adenoma differed by other potential modifiers by creating an interaction term between years of multivitamin use and these variables. We then performed one degree of freedom likelihood ratio tests comparing a fully adjusted multivariable model with years of multivitamin use considered as a continuous variable with a second model with the same variables as previously mentioned and the interaction term.

We tested for trend after excluding non-multivitamin users and using duration of years of multivitamin use as a continuous variable in our multivariate logistic models. All reported $P$-values are two-sided. We conducted all analyses using SAS version 9 (SAS Institute, Inc., Cary, NC, USA).

\section{RESULTS}

Table 1 shows the age-standardized characteristics of women at time of their first endoscopies according to categories of total years of multivitamin use. Women who took multivitamins for the longest duration at the time of their endoscopy, 20-26 years, were more likely to have had a lower BMI, engaged in physical activity for more hours per week, had fewer pack-years of smoking, have been current or past aspirin users, and consumed more calcium, vitamin $\mathrm{D}$, and dietary folate than women with fewer years of multivitamin use. These differences were relatively small. After adjusting for potentially confounding variables, an inverse association for multivitamin use and risk of colorectal adenoma was found when compared with never users multivariable adjusted $(\mathrm{RR}=0.86$, 95\% CI: 0.76-0.97) (Table 2). The longest duration of multivitamin use was suggestive of the largest inverse association with the risk of colorectal adenoma (20-26 years; $R R=0.80,95 \%$ CI: $0.64,1.01)$, although there was no significant trend with years of use (test for linear trend among users $P=0.87$ ) (Table 2).

In the proximal colon, the longest duration of multivitamin use for 20-26 years was also suggestive of an inverse association with the risk of adenoma $\left(\mathrm{RR}_{\text {proximal }}=0.76,95 \% \mathrm{CI}\right.$ : 0.55-1.06), and as with the total adenoma analysis, there was no significant linear trend $(P=0.92)$. Suggestive inverse associations between adenoma found in the distal colon and categories of duration of multivitamin use were estimated with the strongest appearing in the shortest period of time of 4 years or less $\left(\mathrm{RR}_{\text {distal }}=0.78,95 \% \mathrm{CI}\right.$ : $0.65-0.94$ ) (Table 2). There were suggestive inverse associations between adenoma in the rectum and most categories of multivitamin use; however, there was no clear pattern with the duration of use (Table 2). The numbers of adenoma in the rectum are small which may make these associations more difficult to interpret.

We evaluated the association between the use of multivitamins and size of adenomas. The magnitude of the association with multivitamin use for 4 years or less was stronger for large adenoma compared with small adenoma $\left(\mathrm{RR}_{\text {large }}=0.75,95 \%\right.$ CI: 0.58-0.96), but there was no trend with increasing use ( $\left.\mathrm{P}_{\text {trend }}=0.98\right)$; $\left(\mathrm{RR}_{\text {small }}=0.86,95 \%\right.$ CI: 0.73, 1.01; $\left.\mathrm{P}_{\text {trend }}=0.35\right)($ Table 3$)$. When we evaluated ever compared with never multivitamin users, there was a significant inverse association with large adenomas and marginal with small adenomas $\left(\mathrm{RR}_{\text {large }}=0.79,95 \% \mathrm{CI}\right.$ : $0.63,0.98$; $\mathrm{RR}_{\text {small }}=0.88,95 \%$ CI: $0.76,1.01$ ) (Table 3).

The association of multivitamin use for high-risk adenoma appeared strongest in the shortest time period of 4 years or less $\left(\mathrm{RR}_{\text {high risk }}=0.77,95 \% \mathrm{CI}: 0.61,0.97\right)$; conversely for low-risk adenoma, multivitamin use only became significant in the longest years of use category (RR 20-26 years low risk $=0.69,95 \%$ CI: 0.50 , $\left.0.95 ; \mathrm{P}_{\text {trend }}=0.40\right)($ Table 3$)$.

No significant difference in the relationship between multivitamin use and risk of colorectal adenoma was found when analyses were stratified by family history of colorectal cancer $\left(P_{\text {family history }}=0.98\right)$. Associations between multivitamin use and risk of adenoma did not also differ by levels of physical activity $\left(P_{\text {physical activity }}=0.24\right)$, intake of retinol $\left(P_{\text {retinol }}=0.51\right)$, dietary folate, and alcohol $\left(P_{\text {folate }}=0.61, P_{\text {alcohol }}=0.21\right)$ (Table 4$)$.

\section{DISCUSSION}

In this large prospective study of women, 20 years or more of multivitamin use was suggestive of a $20 \%$ lower risk of colorectal adenoma. There was also suggestion of lower risk of adenoma after a longer latency period in the proximal colon and with low-risk adenoma. A short period of 4 years or less of multivitamin use was associated with a reduced risk with adenoma in the distal colon as well as with large $(\geqslant 1 \mathrm{~cm})$ and high risk (large or villous histology 


\begin{tabular}{|c|c|c|c|c|c|c|}
\hline & \multicolumn{6}{|c|}{ Years of multivitamin use at the time of endoscopy } \\
\hline & None & $1-4$ & $5-9$ & $10-14$ & $15-19$ & $20-26$ \\
\hline Participants (n) & 6930 & 11277 & 9789 & 7260 & 3763 & 2384 \\
\hline Mean age (years) & 45.9 & 46.3 & 48.2 & 48.3 & 49.1 & 50.9 \\
\hline Family history of colorectal cancer (\%) & 7.5 & 6.5 & 5.8 & 5.4 & 5.5 & 4.5 \\
\hline Reason for endoscopy is screening (\%) & 68.5 & 69.2 & 70.0 & 70.0 & 69.3 & 72.0 \\
\hline Height (inches) & 64.8 & 64.8 & 65.0 & 65.0 & 65.0 & 63.3 \\
\hline Body mass index $\left(\mathrm{kg} \mathrm{m}^{-2}\right)$ & 26.9 & 27.2 & 26.9 & 26.5 & 26.2 & 25.1 \\
\hline Physical activity (METs hours per week) & 16.8 & 17.4 & 18.9 & 20.0 & 20.8 & 22.1 \\
\hline Smoking (pack-years) & 9.0 & 8.6 & 7.9 & 8.1 & 7.6 & 6.5 \\
\hline \multicolumn{7}{|l|}{ Aspirin use (\%) } \\
\hline $\begin{array}{l}\text { Never use } \\
\text { Past use } \\
\text { Current use ( } \geqslant 1 \text { per week) }\end{array}$ & $\begin{array}{l}53.8 \\
24.2 \\
22.0\end{array}$ & $\begin{array}{l}50.0 \\
26.6 \\
23.4\end{array}$ & $\begin{array}{l}43.3 \\
28.1 \\
28.6\end{array}$ & $\begin{array}{l}41.8 \\
29.7 \\
28.5\end{array}$ & $\begin{array}{l}38.5 \\
32.0 \\
29.5\end{array}$ & $\begin{array}{l}32.9 \\
33.2 \\
33.9\end{array}$ \\
\hline Calcium (mg per day) & 922 & 1035 & 1156 & 1260 & 1315 & 1359 \\
\hline Vitamin D (IUs per day) & 236 & 322 & 411 & 488 & 523 & 546 \\
\hline Red meat (servings per day) & 0.94 & 1.05 & 1.14 & 1.15 & 1.27 & 1.43 \\
\hline Processed meat (servings per day) & 0.17 & 0.17 & 0.16 & 0.16 & 0.15 & 0.14 \\
\hline Alcohol (g per day) & 3.6 & 3.7 & 3.8 & 3.9 & 4.1 & 3.9 \\
\hline Dietary folate $(\mathrm{mcg} \text { per day) })^{a}$ & 306 & 314 & 322 & 329 & 330 & 333 \\
\hline UV-B flux (Robertson-Berger meter units) & 124 & 124 & 125 & 126 & 127 & 123 \\
\hline
\end{tabular}

or high-grade dysplasia) adenoma individually. We also noted a strong association between multivitamin use and reduced risk of colorectal adenoma among those who drank alcohol.

Most studies of cancer observed a long latency period of multivitamin use before observing lower colon cancer incidence or mortality (Neuhouser et al, 2009; Park et al, 2010; Lee et al, 2011; Gaziano et al, 2012). A pooled analysis of 13 cohort studies found that multivitamin use after 7-20 years of follow-up was associated with a reduced risk of colon cancer (RR 0.88, 95\% 0.81-0.96) (Park et al, 2010). However, a recent randomized controlled trial of multivitamin use followed men for an average of 11 years and did not find an association with colorectal cancer (multivitamin vs placebo groups, 1.2 vs 1.4 events, per 1000 person-years; HR, 0.89; 95\% CI, 0.68-1.17; $P=0.39$ ), although the magnitude of the RR was compatible with the observational data (Gaziano et al, 2012). A shorter duration of use, median of 8 years, was not found to be associated with the risk of colorectal cancer in the Women's Health Initiative cohorts (RR 0.99, 95\% CI 0.88-1.11) (Neuhouser et al, 2009). Last, an investigation using the NHS and HPFS cohorts found that duration of multivitamin use appeared to be associated with colorectal cancer only after 16 years or longer of use $\left(\mathrm{RR}_{16-19}\right.$ years $=0.71,95 \%$ CI: $0.53,0.96 ; R_{>20}$ years $=0.77,95 \%$ CI: 0.64 , $0.94)$ (Lee et al, 2011). That same study also examined associations between the duration of multivitamin use and the risk colorectal adenoma and found a shorter period of use was associated with a $27 \%$ lower risk after at least 6-9 years (Lee et al, 2011). On the other hand, a recent study of cancer mortality which pooled 70000 individuals from randomized control trials found no association between multivitamin use and death from any cancer (RR: 0.96; 95\% CI: 0.88, 1.04) (Macpherson et al, 2013).

The findings from our study support those of the studies in colorectal cancer and suggest that compounds in multivitamins may have long-term effects on the risk of adenoma. We did not find a trend with years of usage, only a suggestion in the longest time period of usage. The short temporal relationship between multivitamin use and colorectal adenoma reported from the NHS and HPFS cohorts (Lee et al, 2011) is most similar to what we found in NHS II with regard to risk of large and high-risk adenoma. We may see a pattern of long-term effects of multivitamins to reduce overall risk of adenoma and low-risk adenoma and short-term effects for high-risk adenoma because of the multiple factors acting within a multivitamin. For example, folic acid in multivitamins could be protective early and reduce the risk of high-risk adenoma, but it may take time to observe this effect for all adenomas, especially low-risk adenoma. However, there could be another factor, such as vitamin D, which could help prevent the progression of small into large adenomas (Wei et al, 2008).

Possible pathways through which folic acid in multivitamins could influence colorectal adenoma occurrence includes its crucial role in one-carbon metabolism, that is, DNA synthesis, methylation, and repair (Giovannucci, 2002; McGlynn et al, 2013). Chromosomal breakage and uracil misincorporation into DNA can occur with a deficiency of folate, and folic acid supplementation can reverse this (Blount et al, 1997; Ames, 2001). 1973 was the first year that it was permissible to add up to $400 \mu \mathrm{g}$ of folic acid to vitamin supplements in the United States (US Food and Drug Administration, 1973); therefore, our study encompassed a period when most multivitamins contained $400 \mu \mathrm{g}$ of folic acid. In a pooled analysis of three randomized trials, participants who took folic acid supplementation ( 0.5 or $1.0 \mathrm{mg}$ per day) had no reduction in risk of recurrent adenoma after up to 3.5 years of follow-up (Figueiredo et al, 2011). In addition, animal models have shown that folate inhibits only early stages of colorectal carcinogenesis (Song, 2000). When colorectal neoplasms are already present, excess folate may act as a short-term tumour 
Table 2. RR of colorectal adenoma among women in the NHS II, 1991-2005, by total years of multivitamin use

$\mathrm{RR}$ and $(95 \% \mathrm{Cl})$ by category

\begin{tabular}{|c|c|c|c|c|c|c|c|c|}
\hline & 0 years & $1-4$ years & 5-9 years & $10-14$ years & 15-19 years & $20-26$ years & $\boldsymbol{P}$ trend $^{\mathrm{a}}$ & Ever/never user \\
\hline \multicolumn{9}{|l|}{ Adenoma $^{b}$} \\
\hline $\begin{array}{l}\text { No. of cases/no. of controls } \\
\text { Age-adjusted } R^{c} \\
\text { Multivariable } R^{d} \\
\text { Multivariable } R^{e}\end{array}$ & $\begin{array}{l}413 / 6541 \\
1.00 \\
1.00 \\
1.00\end{array}$ & $\begin{array}{c}581 / 10717 \\
0.82(0.72-0.93) \\
0.83(0.72-0.94) \\
0.84(0.74-0.96)\end{array}$ & $\begin{array}{c}559 / 9247 \\
0.83(0.73-0.95) \\
0.86(0.75-0.98) \\
0.89(0.77-1.02)\end{array}$ & $\begin{array}{c}400 / 6871 \\
0.79(0.68-0.91) \\
0.82(0.71-0.95) \\
0.86(0.74-1.01)\end{array}$ & $\begin{array}{c}200 / 3569 \\
0.77(0.64-0.91) \\
0.80(0.67-0.96) \\
0.85(0.70-1.02)\end{array}$ & $\begin{array}{c}124 / 2265 \\
0.69(0.56-0.86) \\
0.75(0.61-0.94) \\
0.80(0.64-1.01)\end{array}$ & $\begin{array}{l}0.10 \\
0.35 \\
0.87\end{array}$ & $\begin{array}{c}1864 / 32669 / 413 / 654 \\
0.80(0.72-0.90) \\
0.83(0.74-0.93) \\
0.86(0.76-0.97)\end{array}$ \\
\hline
\end{tabular}

Proximal colon

\begin{tabular}{|l|c|c|c|c|c|c|c|c|}
\hline No. of cases/no. of controls & $164 / 6541$ & $247 / 10717$ & $246 / 9247$ & $190 / 6871$ & $106 / 2158$ & $58 / 2265$ & $847 / 32669 / 164 / 6541$ \\
Age-adjusted RR & 1.00 & $0.84(0.69-1.03)$ & $0.83(0.68-1.02)$ & $0.85(0.69-1.05)$ & $0.90(0.70-1.16)$ & $0.68(0.50-0.92)$ & 0.34 & $0.84(0.70-1.00)$ \\
Multivariable RR & 1.00 & $0.85(0.69-1.04)$ & $0.86(0.70-1.06)$ & $0.89(0.71-1.11)$ & $0.93(0.72-1.20)$ & $0.73(0.53-1.00)$ & 0.71 & $0.86(0.72-1.03)$ \\
Multivariable RR & 1.00 & $0.86(0.70-1.05)$ & $0.88(0.71-1.08)$ & $0.91(0.73-1.14)$ & $0.96(0.74-1.25)$ & $0.76(0.55-1.06)$ & 0.92 & $0.88(0.73-1.05)$ \\
\hline
\end{tabular}

\section{Distal colon} Age-adjusted RR

Multivariable $\mathrm{RR}^{\mathrm{d}}$

Multivariable $\mathrm{RR}^{\mathrm{e}}$

\begin{tabular}{|c|c|c|}
\hline $219 / 6541$ & $278 / 10717$ & $284 / 9247$ \\
1.00 & $0.75(0.62-0.90)$ & $0.85(0.71-1.02)$ \\
1.00 & $0.77(0.64-0.92)$ & $0.88(0.73-1.05)$ \\
1.00 & $0.78(0.65-0.94)$ & $0.92(0.76-1.11)$ \\
\hline
\end{tabular}

$179 / 6871$

\begin{tabular}{l|l}
$0.72(0.58-0.88)$ & $90 / 2158$
\end{tabular}

$0.74(0.60-0.91)$

$0.79(0.64-0.98)$

$90 / 2158$
$0.70(0.54-0.90)$
$0.75(0.58-0.97)$
$0.81(0.62-1.06)$

$57 / 2265$ $0.68(0.50-0.92)$

$0.75(0.55-1.02)$

$0.83(0.60-1.14)$

\begin{tabular}{c|c} 
& \\
0.31 & $888 / 32669 / 219 / 6541$ \\
0.62 & $0.76(0.65-0.89)$ \\
0.66 & $0.79(0.67-0.92)$ \\
& $0.83(0.70-0.97)$
\end{tabular}

\section{Rectum}

No. of cases/no, of controls

Age-adjusted RR

Multivariable $\mathrm{RR}^{\mathrm{d}}$

Multivariable $\mathrm{RR}^{\mathrm{e}}$

\section{$70 / 654$}

1.00
1.00

1.00

\begin{tabular}{|c|c|}
\hline $112 / 10717$ & $88 / 9247$ \\
$0.94(0.70-1.28)$ & $0.80(0.58-1.10)$ \\
$0.96(0.70-1.30)$ & $0.84(0.61-1.17)$ \\
$0.96(0.71-1.30)$ & $0.85(0.62-1.18)$
\end{tabular}

$76 / 6871$
$0.93(0.66-1.30)$
$1.00(0.71-1.41)$

\begin{tabular}{l|l}
$1.00(0.71-1.41)$ & $0.73(0.46-1.15)$ \\
$1.01(0.72-1.42)$ & $0.73(0.46-1.15)$
\end{tabular}

$0.73(0.46-1.15)$
$0.73(0.46-1.15)$

$24 / 2265$
$0.85(0.52-1.37)$
$0.96(0.59-1.57)$
$0.97(0.60-1.59)$

$0.96(0.59-1.57)$

$0.97(0.60-1.59)$

\begin{tabular}{c|c} 
& $328 / 32669 / 70 / 6541$ \\
0.41 & $0.87(0.66-1.13)$ \\
0.77 & $0.91(0.70-1.19)$ \\
0.76 & $0.92(0.70-1.21)$ \\
\hline
\end{tabular}

${ }^{\text {a }}$ Calculated excluding non-multivitamin users and using years of multivitamin use as a continuous variable.

badenoma found in proximal and/or distal colon and/or rectum.

cOdds ratio and $95 \% \mathrm{Cl}$ from age, time-period-adjusted logistic regression.

dOdds ratio and $95 \% \mathrm{Cl}$ from model above (c) additionally controlling for non-dietary covariates: family history of colorectal cancer, height, reason for endoscopy, BMI, physical activity, pack years of smoking, aspirin use, and UV-B flux.

'Odds ratio and $95 \% \mathrm{Cl}$ from model above (d) additionally controlling for intakes of energy adjusted calcium, folate from food, alcohol, red meat, and processed meats.

Table 3. Relative risk of large $(\geqslant 1 \mathrm{~cm})$ and small $(<1 \mathrm{~cm})$, high-risk (large or villous histology or high grade dysplasia) and low-risk (small and tubular) colorectal adenoma among women in the Nurses' Health Study II, 1991-2005, by total years of multivitamin use

RR and $(95 \% \mathrm{Cl})$ by category

\begin{tabular}{|l|l|l|l|l|l|l|l|}
\hline 0 years & 1-4 years & $5-9$ years & $10-14$ years & 15-19 years & $20-26$ years & $\boldsymbol{P}$ trend & Ever/never users $^{\text {a }}$ \\
\hline
\end{tabular}

Adenoma $^{\mathrm{b}}$

\section{Large}

\begin{tabular}{|l|c|c|c|c|c|c|c|c|}
\hline $\begin{array}{l}\text { No. of cases/no. of controls } \\
\text { Multivariable RR }\end{array}$ & $119 / 6541$ & $139 / 10717$ & $135 / 9247$ & $97 / 6871$ & $43 / 3569$ & $23 / 2265$ & $556 / 32669 / 119 / 6541$ \\
\hline
\end{tabular}

\section{Small}

\begin{tabular}{|l|c|c|c|c|c|c|c|c|}
\hline $\begin{array}{l}\text { No. of cases/no. of controls } \\
\text { Multivariable RR }\end{array}$ & $274 / 6541$ & $404 / 10717$ & $400 / 9247$ & $277 / 6871$ & $149 / 3569$ & $95 / 2265$ & $1599 / 32669 / 274 / 6541$ \\
\hline
\end{tabular}

\section{High risk}

Multivariable RR $^{c}$

\begin{tabular}{|c|r|r}
\hline $142 / 6729$ & $171 / 10990$ & $164 / 9531$ \\
\hline
\end{tabular}

\begin{tabular}{l|l}
1.00 & $0.77(0.61-0.97)$
\end{tabular}

$0.87(0.68-1.10)$

$0.91(0.70-1.19)$

\begin{tabular}{c|c}
$0.91(0.70-1.25)$ & $21 / 2321$ \\
$0.91(0.61-1.35)$
\end{tabular}

0.16

$696 / 33571 / 142 / 6729$

Low risk

No. of cases/no. of controls

Multivariable RR

\begin{tabular}{|c|c|c|}
\hline $188 / 6683$ & $273 / 10888$ & $284 / 9411$
\end{tabular}

\begin{tabular}{c|r}
$96 / 3631$ & $56 / 2301$
\end{tabular}

$56 / 2301$
$.69(0.50-0.95)$

0.40

$1090 / 33223 / 188 / 6683$ $0.84(0.71-1.00)$

${ }^{a}$ Calculated excluding non-multivitamin users using years of multivitamin use as a continuous variable.

${ }^{\mathbf{b}}$ Adenoma found in proximal and/or distal colon and/or rectum.

c Odds ratio and $95 \% \mathrm{Cl}$ from logistic regression adjusted for covariates mentioned in Table 2.

promoter, possibly related to its disruption of one-carbon transfer reactions (Kim, 2003, 2007). However, we did not observe any adverse effect of multivitamin use. This is especially noteworthy considering our study population was consuming even greater amounts of folate beyond those from multivitamins during this study period as folate fortification of US breads, cereals, and other grains began in 1997 (US Food and Drug Administration, 1996). In addition, we found a stronger inverse association between 
Table 4. Relative risk of colorectal adenoma among women in the NHS II, 1991-2007, by 20-26 years vs never use and ever vs never use of

multivitamins stratified by family history, physical activity and intakes of retinol, folate from food (not supplements), and alcohol

\begin{tabular}{|c|c|c|}
\hline \multirow[b]{2}{*}{ Adenoma $^{a}$} & \multicolumn{2}{|c|}{$\mathrm{RR}$ and $(95 \% \mathrm{Cl})$} \\
\hline & $\begin{array}{c}20-26 \text { years/ } \\
\text { never use }\end{array}$ & Ever/never use \\
\hline \multicolumn{3}{|l|}{ Family history (yes) } \\
\hline $\begin{array}{l}\text { No. of cases/no. of controls } \\
\text { Multivariable RR }\end{array}$ & $\begin{array}{c}16 / 150 / 108 / 1188 \\
1.13(0.62-2.06)\end{array}$ & $\begin{array}{c}358 / 4595 / 108 / 1188 \\
0.88(0.69-1.12)\end{array}$ \\
\hline \multicolumn{3}{|l|}{ Family history (no) } \\
\hline $\begin{array}{l}\text { No. of cases/no. of controls } \\
\text { Multivariable RR }\end{array}$ & $\begin{array}{c}108 / 2115 / 305 / 5353 \\
0.77(0.60-0.98)\end{array}$ & $\begin{array}{c}1506 / 28074 / 305 / 5353 \\
0.86(0.75-0.99)\end{array}$ \\
\hline \multicolumn{3}{|c|}{ High physical activity ( $\geqslant 14.5$ METs hours per week) } \\
\hline $\begin{array}{l}\text { No. of cases } / \mathrm{no} \text { of controls } \\
\text { Multivariable } \mathrm{RR}^{\mathrm{b}}\end{array}$ & $\begin{array}{c}57 / 1099 / 132 / 2303 \\
0.72(0.52-0.99)\end{array}$ & $\begin{array}{c}713 / 13491 / 132 / 2303 \\
0.76(0.63-0.92)\end{array}$ \\
\hline \multicolumn{3}{|c|}{ Low physical activity ( $<14.5$ METs hours per week) } \\
\hline $\begin{array}{l}\text { No. of cases/no. of controls } \\
\text { Multivariable } R^{b}\end{array}$ & $\begin{array}{c}66 / 1162 / 280 / 4215 \\
0.84(0.60-1.16)\end{array}$ & $\begin{array}{c}1148 / 19120 / 280 / 4215 \\
0.92(0.79-1.07)\end{array}$ \\
\hline \multicolumn{3}{|l|}{ High retinol( $\geqslant 2913 \mathrm{IU})$} \\
\hline $\begin{array}{l}\text { No. of cases/ no. of controls } \\
\text { Multivariable RR }\end{array}$ & $\begin{array}{c}113 / 1992 / 44 / 830 \\
1.00(0.69-1.47)\end{array}$ & $\begin{array}{c}1052 / 18821 / 44 / 830 \\
1.00(0.73-1.38)\end{array}$ \\
\hline \multicolumn{3}{|l|}{ Low retinol (<2913 IU) } \\
\hline $\begin{array}{l}\text { No. of cases } / n \text {. of controls } \\
\text { Multivariable } R^{b}\end{array}$ & $\begin{array}{c}11 / 273 / 369 / 5711 \\
0.54(0.29-1.00)\end{array}$ & $\begin{array}{c}812 / 13848 / 369 / 5711 \\
0.82(0.71-0.94)\end{array}$ \\
\hline \multicolumn{3}{|c|}{ High dietary folate ( $\geqslant 314 \mathrm{mcg}$ per day) } \\
\hline $\begin{array}{l}\text { No. of cases } / \mathrm{no} \text {. of controls } \\
\text { Multivariable } \mathrm{RR}^{\mathrm{b}}\end{array}$ & $\begin{array}{c}86 / 1476 / 171 / 2637 \\
0.85(0.63-1.02)\end{array}$ & $\begin{array}{c}937 / 16989 / 171 / 2637 \\
0.80(0.67-0.96)\end{array}$ \\
\hline \multicolumn{3}{|c|}{ Low dietary folate ( $<314 \mathrm{mcg}$ per day) } \\
\hline $\begin{array}{l}\text { No. of cases/no. of controls } \\
\text { Multivariable RR }\end{array}$ & $\begin{array}{c}38 / 789 / 242 / 3904 \\
0.85(0.63-1.14)\end{array}$ & $\begin{array}{c}927 / 15680 / 242 / 3904 \\
0.90(0.77-1.06)\end{array}$ \\
\hline \multicolumn{3}{|l|}{$\geqslant 1.4 \mathrm{~g}$ per day alcohol } \\
\hline $\begin{array}{l}\text { No. of cases/no. of controls } \\
\text { Multivariable } R^{b}\end{array}$ & $\begin{array}{l}63 / 1261 / 199 / 2989 \\
0.67(0.49-0.91)\end{array}$ & $\begin{array}{l}979 / 16677 / 199 / 2989 \\
0.82(0.70-0.98)\end{array}$ \\
\hline \multicolumn{3}{|l|}{$<1.4 \mathrm{~g}$ per day alcohol } \\
\hline $\begin{array}{l}\text { No. of cases } / \mathrm{no} \text { of controls } \\
\text { Multivariable } \mathrm{RR}^{\mathrm{b}}\end{array}$ & $\begin{array}{c}61 / 1004 / 214 / 3552 \\
1.00(0.73-1.38)\end{array}$ & $\begin{array}{c}885 / 15992 / 214 / 3552 \\
0.90(0.76-1.06)\end{array}$ \\
\hline \multicolumn{3}{|c|}{$\begin{array}{l}\text { a Adenoma found in proximal and/or distal colon and/or rectum. } \\
\text { b } \\
\text { Tablds ratio and } 95 \% \mathrm{Cl} \text { from logistic regression adjusted for: covariates mentioned in } \\
\text { Models that are stratified by family history, physical activity, and intakes of retinol, folate, } \\
\text { and alcohol do not adjust for these stratified variables in their model. Categories were } \\
\text { determined by median values. } \\
\text { Tests for effect modification } 26-20 / 0 \text { years use: } P_{\text {family history }}=0.98 ; P_{\text {phyical activity }}=0.24 \\
P_{\text {retinol }}=0.51 ; P_{\text {Folate }}=0.61 ; P_{\text {Alcohol }}=0.21 \text {. }\end{array}$} \\
\hline
\end{tabular}

multivitamin use and reduced risk of adenoma among those who consumed $\geqslant 1.4 \mathrm{~g}$ per day of alcohol. Alcohol is an established folate antagonist and there is consistent evidence that a combination of alcohol consumption and low folate intakes are associated with an increased risk of colorectal cancer (Giovannucci and Willett, 1994; Giovannucci et al, 1995; La Vecchia et al, 2002). It would follow that the folic acid in multivitamins would be particularly important in colorectal adenoma incidence reduction among those in a possible depleted state due to alcohol consumption.

Other important components in multivitamins include vitamin B6, which is involved in DNA synthesis and methylation
(Zhang et al, 2006). Vitamin D is an usual component of multivitamins and is thought to accelerate apoptosis in colorectal mucosa and may also reduce risk of colorectal cancer through its role in cell differentiation and proliferation (Lamprecht and Lipkin, 2001; Holt et al, 2002; Grant and Garland, 2004; Harris and Go, 2004; Giovannucci, 2006b). Lastly, vitamins C, E, and betacarotene found in multivitamins have numerous biological activities that are thought to be important in cancer prevention such as trapping free radicals, assisting in cell communication, and activating the immune system (van Poppel and van den Berg, 1997). Because most multivitamins contain several of these vitamins, it is not possible to separate their independent effects.

To our knowledge, this is the first prospective study to investigate the relation of long-term use of multivitamins on risk of colorectal adenoma in a cohort of younger women. Strengths of our study include its prospective design, large sample size, a high follow-up response rate, use of first endoscopy procedure, repeated assessments of multivitamin use, and detailed repeated data on many potential confounders. These factors reduce the chance that bias or residual confounding influenced our results.

'Health conscious' behaviours such as physical activity, aspirin use, and low pack years of cigarette smoking were all slightly more prevalent among participants with the longest duration of multivitamin use. These lifestyle factors were controlled for in this study; yet it is possible that there was some residual confounding due to errors in measurement of these covariates. However, we found only small differences in magnitude of associations between the ageadjusted analyses and the multivariate analyses that controlled for these 'health conscious' traits suggesting potential residual confounding unlikely explained our results.

One limitation of our study is that duration of multivitamin use was assessed by questionnaires which are likely to result in some misclassification of exposure. However, misclassification of exposure should not be associated with the outcome because our study design was prospective. Therefore, misclassification of exposure would tend to bias the results towards the null. Another limitation is that the study was comprised of young women only; therefore, the results may not be generalisable to older women or to men. In addition, because this is an observational study we can only assess the associations between multivitamin use and colorectal adenoma occurrence and not causal relationships.

In conclusion, our results suggest that 20 years or more of multivitamin use is associated with reduced risk of colorectal adenoma in young women; with shorter durations needed for large and high-risk adenoma. Further studies are needed to better define the duration of use that is required before potential protective effects of multivitamin use can be detected, and whether timing of exposure or duration of exposure is the critical factor in the reduction of risks. The specific components of multivitamins that may reduce the risk need to be identified. This information may be relevant to the conduct of randomized control trials with adenomas as the endpoint.

\section{ACKNOWLEDGEMENTS}

We appreciate the contributions of Gary Chase, Karen Corsano, and Scott Smith for their expert help. This work was supported by research grants: R01 CA50385; CA55075; R02 CA125837/ CA151993 from the National Institutes of Health.

\section{REFERENCES}

AGRICULTURE, U. S. D. O (1989) Composition of foods-raw, processed, and prepared, 1963-1988 Agricultural Handbook No. 8 Series. Washington, DC: Department of Agriculture, US Gov Pr Office. 
Ames BN (2001) DNA damage from micronutrient deficiencies is likely to be a major cause of cancer. Mutat Res 475: 7-20.

Blount BC, Mack MM, Wehr CM, Macgregor JT, Hiatt RA, Wang G, Wickramasinghe SN, Everson RB, Ames BN (1997) Folate deficiency causes uracil misincorporation into human DNA and chromosome breakage: implications for cancer and neuronal damage. Proc Natl Acad Sci USA 94: 3290-3295.

Chlebowski RT, Wactawski-Wende J, Ritenbaugh C, Hubbell FA, Ascensao J, Rodabough RJ, Rosenberg CA, Taylor VM, Harris R, Chen C, Adams-Campbell LL, White E (2004) Estrogen plus progestin and colorectal cancer in postmenopausal women. $N$ Engl J Med 350: 991-1004.

Colditz GA, Hankinson SE (2005) The Nurses' Health Study: lifestyle and health among women. Nat Rev Cancer 5: 388-396.

Figueiredo JC, Mott LA, Giovannucci E, Wu K, Cole B, Grainge MJ, Logan RF, Baron JA (2011) Folic acid and prevention of colorectal adenomas: a combined analysis of randomized clinical trials. Int J Cancer 129: 192-203.

Gaziano JM, Sesso HD, Christen WG, Bubes V, Smith JP, Macfadyen J, Schvartz M, Manson JE, Glynn RJ, Buring JE (2012) Multivitamins in the prevention of cancer in men: the Physicians' Health Study II randomized controlled trial. JAMA 308: 1871-1880.

Giovannucci E (2002) Epidemiologic studies of folate and colorectal neoplasia: a review. J Nutr 132: 2350S-2355S.

Giovannucci E (2006a) The epidemiology of vitamin D and colorectal cancer: recent findings. Curr Opin Gastroenterol 22: 24-29.

Giovannucci E (2006b) The epidemiology of vitamin D and colorectal cancer: recent findings. Curr Opin Gastroenterol 22: 24-29.

Giovannucci E, Rimm EB, Ascherio A, Stampfer MJ, Colditz GA, Willett WC (1995) Alcohol, low-methionine-low-folate diets, and risk of colon cancer in men. J Natl Cancer Inst 87: 265-273.

Giovannucci E, Stampfer MJ, Colditz GA, Hunter DJ, Fuchs C, Rosner BA, Speizer FE, Willett WC (1998) Multivitamin use, folate, and colon cancer in women in the Nurses' Health Study. Ann Intern Med 129: 517-524.

Giovannucci E, Stampfer MJ, Colditz GA, Rimm EB, Trichopoulos D, Rosner BA, Speizer FE, Willett WC (1993) Folate, methionine, and alcohol intake and risk of colorectal adenoma. J Natl Cancer Inst 85: 875-884.

Giovannucci E, Willett WC (1994) Dietary factors and risk of colon cancer. Ann Med 26: 443-452.

Grant WB, Garland CF (2004) A critical review of studies on vitamin D in relation to colorectal cancer. Nutr Cancer 48: 115-123.

Harris DM, Go VL (2004) Vitamin D and colon carcinogenesis. J Nutr 134: 3463S-3471S.

Holt PR, Arber N, Halmos B, Forde K, Kissileff H, Mcglynn KA, Moss SF, Kurihara N, Fan K, Yang K, Lipkin M (2002) Colonic epithelial cell proliferation decreases with increasing levels of serum 25-hydroxy vitamin D. Cancer Epidemiol Biomarkers Prev 11: 113-119.

Jacobs EJ, Connell CJ, Chao A, Mccullough ML, Rodriguez C, Thun MJ, Calle EE (2003) Multivitamin use and colorectal cancer incidence in a US cohort: does timing matter? Am J Epidemiol 158: 621-628.

Jacobs EJ, Connell CJ, Patel AV, CHAO A, Rodriguez C, Seymour J, Mccullough ML, Calle EE, Thun MJ (2001) Multivitamin use and colon cancer mortality in the Cancer Prevention Study II cohort (United States). Cancer Causes Control 12: 927-934.

Kim YI (2003) Role of folate in colon cancer development and progression. J Nutr 133: 3731S-3739S.

Kim YI (2007) Folate and colorectal cancer: an evidence-based critical review. Mol Nutr Food Res 51: 267-292.

LA Vecchia C, Negri E, Pelucchi C, Franceschi S (2002) Dietary folate and colorectal cancer. Int J Cancer 102: 545-547.

Lamprecht SA, Lipkin M (2001) Cellular mechanisms of calcium and vitamin D in the inhibition of colorectal carcinogenesis. Ann N Y Acad Sci 952: 73-87.

Lamprecht SA, Lipkin M (2003) Chemoprevention of colon cancer by calcium, vitamin D and folate: molecular mechanisms. Nat Rev Cancer 3: 601-614.
Lee JE, Willett WC, Fuchs CS, Smith-Warner SA, Wu K, Ma J, Giovannucci E (2011) Folate intake and risk of colorectal cancer and adenoma: modification by time. Am J Clin Nutr 93: 817-825.

Macpherson H, Pipingas A, Pase MP (2013) Multivitamin-multimineral supplementation and mortality: a meta-analysis of randomized controlled trials. Am J Clin Nutr 97: 437-444.

Matsubara K, Komatsu S, Oka T, Kato N (2003) Vitamin B6-mediated suppression of colon tumorigenesis, cell proliferation, and angiogenesis (review). J Nutr Biochem 14: 246-250.

Mcglynn AP, Wasson GR, O'reilly SL, Mcnulty H, Downes CS, Chang CK, Hoey L, Molloy AM, Ward M, Strain JJ, Mckerr G, Weir DG, Scott JM (2013) Low colonocyte folate is associated with uracil misincorporation and global DNA hypomethylation in human colorectum. J Nutr 143: 27-33.

Neuhouser ML, Wassertheil-Smoller S, Thomson C, Aragaki A, Anderson GL, Manson JE, Patterson RE, Rohan TE, Van Horn L, Shikany JM, Thomas A, Lacroix A, Prentice RL (2009) Multivitamin use and risk of cancer and cardiovascular disease in the Women's Health Initiative cohorts. Arch Intern Med 169: 294-304.

Park Y, Spiegelman D, Hunter DJ, Albanes D, Bergkvist L, Buring JE, Freudenheim JL, Giovannucci E, Goldbohm RA, Harnack L, Kato I, Krogh V, Leitzmann MF, Limburg PJ, Marshall JR, Mccullough ML, Miller AB, Rohan TE, Schatzkin A, Shore R, Sieri S, Stampfer MJ, Virtamo J, Weijenberg M, Willett WC, Wolk A, Zhang SM, Smith-Warner SA (2010) Intakes of vitamins A, C, and E and use of multiple vitamin supplements and risk of colon cancer: a pooled analysis of prospective cohort studies. Cancer Causes Control 21: 1745-1757.

Salvini S, Hunter D, Sampson L, Stampfer M, Colditz G, Willett W (1989) Food-based validation of a dietary questionnaire: the effects of week-to-week variation in food consumption. Intl J Epidemiol 18: $858-867$.

Scotto J, Cotton G, Urbach F, Berger D, Fears T (1988) Biologically effective ultraviolet radiation: surface measurements in the United States, 1974 to 1985. Science 239: 762-764.

Song J, Sohn KJ, Ash C, Gallinger S, Kim YI (2000) Chemopreventive effects of dietary folate on intestinal polyps in Apc +/-Msh2-/-mice. Cancer Res 60: 191-199.

US Food and Drug Administration (1973) Statement of general policy or interpretation. Subchapter B - food and food products, part 121 - food additives. Federal Register 38: 20725-20726.

US Food and Drug Administration (1996) Food standards: amendment of standards of identity for enriched grain products to require addition of folic acid. Federal Register 61: 8781-8797.

Van Poppel G, Van Den Berg H (1997) Vitamins and cancer. Cancer Lett 114: 195-202.

Wei MY, Garland CF, Gorham ED, Mohr SB, Giovannucci E (2008) Vitamin $\mathrm{D}$ and prevention of colorectal adenoma: a meta-analysis. Cancer Epidemiol Biomarkers Prev 17: 2958-2969.

White E, Shannon JS, Patterson RE (1997) Relationship between vitamin and calcium supplement use and colon cancer. Cancer Epidemiol Biomarkers Prev 6: 769-774.

Wickramasinghe SN, Fida S (1994) Bone marrow cells from vitamin B12- and folate-deficient patients misincorporate uracil into DNA. Blood 83: 1656-1661.

Willett WC, Sampson L, Stampfer MJ, Rosner B, Bain C, Witschi J, Hennekens CH, Speizer FE (1985) Reproducibility and validity of a semiquantitative food frequency questionnaire. Am J Epidemiol 122: 51-65.

Zhang SM, Moore SC, Lin J, Cook NR, Manson JE, Lee IM, Buring JE (2006) Folate, vitamin B6, multivitamin supplements, and colorectal cancer risk in women. Am J Epidemiol 163: 108-115.

This work is published under the standard license to publish agreement. After 12 months the work will become freely available and the license terms will switch to a Creative Commons AttributionNonCommercial-Share Alike 3.0 Unported License. 